\title{
Ash Contents of Trace Metals and Concentration of Oil in the Fresh Water Fish, Notopterus notopterus
}

\section{Raghavendra Kulkarni*}

Department of Studies in Zoology, Gulbarga University, Kalaburagi, Karnataka, India

*Corresponding Author: Raghavendra Kulkarni, Department of Studies in Zoology, Gulbarga University, Kalaburagi, Karnataka, India.
Received: January 11, 2022

Published: January 31, 2022

(C) All rights are reserved by Raghavendra

Kulkarni.

\begin{abstract}
The ash content refers to the inorganic residue remaining by ignition or complete oxidation is a part of proximate analysis for nutritional evaluation and it is an important quality attribute for some ingredients such as minerals. The ash contents of trace macro, micro metals and whole-body oil concentration was determined in the locally available fresh water fish, Notopterus notopterus. This fish is available in large numbers in the aquatic bodies of Kalaburagi and is being consumed as food fish by local population. The ash content was determined by dry weight method and the contents of trace metals determined in the ash by processing for Atomic Absorption spectrometry (AAS). The total body oil concentration was analyzed by boiling the fish sample and oil was extracted. The total ash was found to be $10 \mathrm{~g} / 100 \mathrm{gm}$ of fish and the trace metals in the ash was chromium, zinc, iron and lead, whereas copper, mercury and cadmium were not detected in the ash. The oil concentration in whole fish was at 2.85 ml. The free fatty acids (FFA) and acid value of the value of the oil was determined and found to be 1.78 (less than 2) and found suitable for edible purpose. The results indicate that the fish, Notopterus notopterus has lesser amount of trace metals and the fish body oil has been extracted with less quantity, may be because of lean body of the fish and it is found to be not a fatty fish. Since the fish has necessary nutritional compositions and this fish can be considered as food fish in the local area.
\end{abstract}

Keywords: Fish Ash; Minerals; Oil; Free Fatty Acids

\section{Introduction}

The basic study related to nutritional compositions of edible fish in the local area is needed for the evaluation and to identify nutritional status. The fish selected in the present study is available in large numbers in the aquatic bodies of Kalaburagi and is being consumed as food fish by local population is also providing nutritional requirement in a lesser price. In addition to biochemical composition studies of fish, investigation on macro and micro mineral contents of the ash and oil concentration of the body is needed as part of proximate analysis for nutritional evaluation and it is an important quality attribute for some food ingredients such as minerals. Fish contributes not only for their high nutritional value but also improving human health status and it is known that fish has been recommended for prevention of many diseases including heart ailments [9]. In this regard some reports are available in relation to specific environmental conditions $[6,12]$. In the present study ash contents of macro and micro mineral contents of the freshwater fish, Notopterus notopterus was analyzed along with total body oil concentration. Such fish oil extraction studies are available on in many marine fish species $[4,5,7]$. The oil content of free fatty acids and acid value was calculated in the fish, Notopterus notopterus by applying specific formula [11].

\section{Material and Methods}

The freshwater fish, Notopterus notopterus bearing 25 numbers having length of $30 \mathrm{~cm}$ and weight of $110 \mathrm{gm}$ was brought from the 
local market in dead condition and processed for the determination of ash content and processed for the oil extraction.

\section{Determination of ash content}

The fish sample was oven dried in an electric oven at between 70- 80-degree temperature until the samples had constant weight and $2 \mathrm{~g}$ was measured and taken as analytical sample, the samples were digested with concentrated nitric acid. The wet method of digestion was used to carry out the sample digestion. The weighed sample was taken, $10 \mathrm{ml}$ of 3:1 acidic mixture was added (nitric acid and perchloric acid). The mixture was then transfer to a hot plate and digested at a temperature of $150^{\circ} \mathrm{C}$ until total dissolution was achieved and till samples became clear. Atomic Absorption Spectroscopy (AAS) was used as described by APHA (1995) to determine the level of various mineral content. The moisture free dried fish sample were grinded and finally powdered with the help of mortar pestle for converting sample into fine powder which was used for the analysis of other parameters such as ash content. Fine powdered moisture free samples were taken in clean pre-weighed silica crucibles and weighed again along with samples. The crucible containing samples was then placed in a muffle furnace at $65{ }^{\circ} \mathrm{C}$ for about 4-6 hours or till the residue became completely white. The sample was then allowed to cool in desiccators for about 2030 minutes reweighed and the amount of ash was calculated as the difference in weight. The percentage of ash was obtained by using the following formula.

Total ash\%-Wt. of ash (g)/Wt. of sample (g) X100. The percentage of mineral elemental concentration including mineral concentration was determined using (AAS) Atomic Absorption Spectrometer (AOAC, 1975).

Method of Oil Extraction: The oil extraction from the fish was determined by cutting the fish into three to four pieces removing all internal organs (head portion not included) and boiled for 45 minutes on a hot plate, cooled for 6-10 hours and later the boiled and cooled sample was pressed in order to extract the oil. The fluid was allowed to settle; the super layer accumulated oil was taken and heated to remove water content, then centrifuged and measured for the amount of oil extracted. The free fatty acids (FFA) and acid value of the oil was calculated. The FFA value was determined according to the method described in AOCS method (AOCS, 1992) by Laila., et al. (2014). An amount of $2.85 \mathrm{ml}$ (2.85gm) of oil sample was mixed with $75 \mathrm{ml}$ of $95 \%$ neutral ethyl alcohol and swirled;
Phenolphthalein was added to the mixed solution as indicator. The solution was titrated with $0.1 \mathrm{~N}$ sodium hydroxide until pinkish colour was observed at the end point. The percentage for FFA was expressed as Oleic acid in the oil.

The FFA was calculated as described [3] following the formula as: Percentage (\%) of FFA as oleic acid = Alkali vol.(ml) X Alkali normality X 28.2/divided by sample weight. The acid value of oil was calculated by following the formula as described [3]: Percentage (\%) of FFA X 1.99.

\section{Results}

The percentage of ash content found for the fish Notopterus notopterus in the present investigation is $34 \%$. The percentage of ash content was determined by weight of the ash divided by the weight of the original sample multiplied by $100 \%$ of sample size. The results are expressed as in gm and in percentage in the table-01. The ash content of macro and micro mineral contents is also presented in the table 1 . The results of mineral concentration indicate that the minerals such as chromium $(0.14 \%)$, zinc $(0.38 \%)$, iron $(0.81 \%)$ lead $(0.02 \%)$ were detected in the ash sample processed by AAS, whereas minerals such as copper, mercury and cadmium were not detected in the ash sample of the fish. Thus, the results indicate the water contents of these minerals which are not detected may not be absorbed by the fish or may be present in very less quantity. Although the minerals such as chromium, zinc, iron and lead were present are in less quantity which may needed for the fish for its regular physiological activities and their presence in the body of fish has also useful for nutritional purpose.

The level of oil concentration in the body of fish, Notopterus notopterus presented in the table- 1 shows that only maximum of $2.85 \mathrm{ml}$ obtained by heat method, since this fish is lean fish having streamline body and not a fatty fish as the fat content is less. The percentage of free fatty acid (FFA) content of the oil was found to be less than $2 \%$ as per calculation mentioned above, considering this fish as lean fish containing less fat. However, the fish Notopterus notopterus can provide minimum required mineral components for self-survival and for nutritional purpose. The free fatty acid is referred as Omega-9 fatty acid (Oleic acid).

\section{Discussion}

The fish has good survival in the aquatic body from which it is being collected indicating that the aquatic body providing all the 


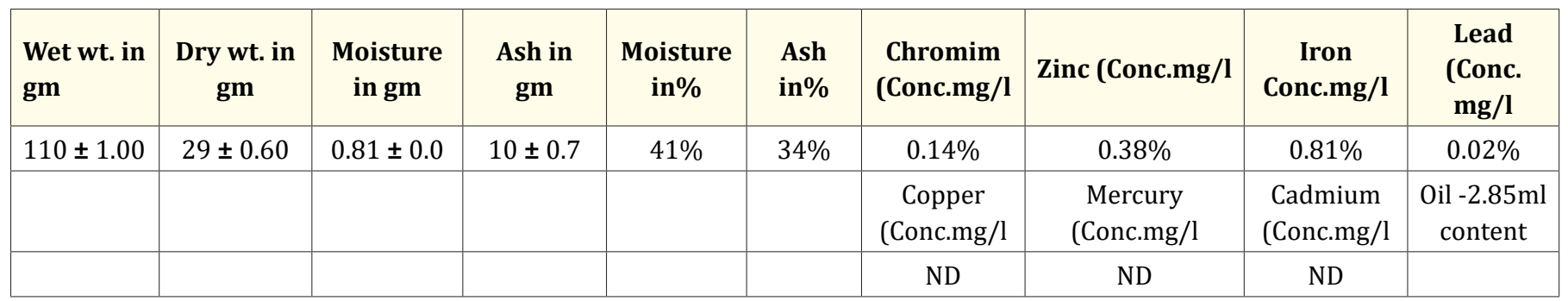

Table 1: Showing wet weight, dry weight, moisture, ash content and oil Concentration in the freshwater fish, Notopterus notopterus. Values are expressed as mean $\pm \mathrm{SD}, \mathrm{N}=06$, ND- Not Detected.

required environmental conditions/factors. The feeding habit of this fish includes insects, plant roots and even small fishes. Based on the feeding habit this fish in the present study can be classified as corni-omnivorous fish. Although age, sex, environmental condition and season will have effect on the chemical compositions and nutritional value of fish [1,2]. The ash content of this is $34 \%$ and the mineral concentration in the ash though in less quantity, the ash has macro and micro minerals such as chromium, zinc, iron, lead, which were detected in the ash sample processed by AAS. It is mostly agreed that fish requires all these minerals including calcium, phosphorous, sodium, potassium and other minerals for development and growth of the skeleton and they act in several other biochemical reactions [8]. The deficiency of these minerals mentioned above causes abnormality and poor health conditions of the fish. The micro minerals which include copper, iodine, iron, manganese, selenium and zinc though present in the fish body in less amounts are being absorbed from feed and water are necessary for various physiological activities.

The fish $N$. notopterus has a streamline body and lean fish and not a fatty fish. Hence, the oil concentration is less. However, the free fatty acid (FFA) concentration was found as per its body size. It is being assessed based on the percentage of oil content in the sample as lean fish and FFA content in the oil has less than $2 \%$ The low fatty fish has FFA as $2-4 \%$, medium fatty fish has $4-8 \%$ and high fatty fish has more than $8 \%$ and it is justified that $N$. notopterus is a lean fish and not a fatty fish, may be FFA is less than $2 \%$. The range of acid value in the oil refers to $1.8 \%$ to $4 \%$, the oil having high FFA acid value at 3.5\% probably not suitable for edible purpose. The free fatty acid present in the oil of fish is oleic acid and oleic acid is a fatty acid occurs in naturally in various animal and vegetable fats and oils. It is an odorless, colorless oil, although commercial samples may be yellowish, it is classified as monounsatu- rated omega -9 fatty acid having boiling point at 360 degrees and insoluble in water [10]. This free fatty acid (FFA) present in fish is being used to replace saturated fats in the diet, improves heart conditions by lowering cholesterol and reducing inflammation and healing wounds, skin repair also effective in dealing with damages caused by by skin diseases like psoriasis and eczema.

\section{Conclusions}

The freshwater fish, Notopterus notopterus investigated for amount of ash content and its macro, micro minerals indicate that needed minerals such as chromium, zinc, iron, lead, were detected in the ash sample processed by AAS. The oil concentration analysis indicate that the oil has free fatty acids which is omega- 9 fatty acid having less acid value is suitable for edible purpose. Hence, in addition to mineral content oil also provides proper nutritional compositions.

\section{Acknowledgements}

The author is grateful to Indian Science Congress Association, Kolkata for Asutosh mookherjee fellowship and to the Gulbarga University, Kalaburagi for providing the facilities.

\section{Bibliography}

1. Ayas D and Ozogul Y. "The chemical composition of carapace meat of sexually mature blue crab (Callinectes sapiidus, Rathabun 1896) in the marine Bay". Journal of Fisheries Science 38 (2011): 645-650.

2. Fawole 00., et al. "Internet Journal of Food Safety 9 (2007): 52.

3. Laila DL., et al. "Application of response surface methodology to optimize the extraction of Asian catfish (Claria batrachus) oil using super-heated stream treatment". Food Science and Technology 2.6 (2014): 69-76. 
4. Maqsood S., et al. "Extraction, processing and stabilization of health- promoting fish oils". Recent Patents on Food and Agriculture 4.2 (2012): 01-07.

5. Mohammad M., et al. "Investigation on fish oil extraction by enzyme extraction and wet reduction method and quality analysis". AACL Bioflux 11.1 (2018).

6. Mohanty BP., et al. "Fish in human health and nutrition". Advances in Fish Research (2019): 189-218.

7. Moorty Praveenkumar., et al. "Extraction of fish body oil from Sardinella longicep by employing direct streaming method and its quantitative and qualitative assessment". Journal of Coastal Life Medicine 3.12 (2015): 962-966.

8. Prabhu E., et al. "An overview on significance of fish nutrition in aquaculture industry". International Journal of Fisheries and Aquatic Studies 6 (2017): 349-355.

9. Rino Susilavati., et al. "Nutritional and albumin content of swamp fishes from Marauke, Papua, Indonesia". Squalen Bulletin of Marine and Fisheries Postharvest and Biotechnology 11.3 (2016): 107-116.

10. Takashi Watanabe., et al. "Trace minerals in fish nutrition". Aquaculture 151.1-4 (1997): 185-207.

11. Tanko Bako., et al. "Criteria for the extraction of fish oil". CIGR Journal 19.3 (2017).

12. Victoria OE and Akpambang. "Proximate composition of some tropical fish species". 6.4 (2015): 125-129.

\section{Assets from publication with us}

- Prompt Acknowledgement after receiving the article

- Thorough Double blinded peer review

- Rapid Publication

- Issue of Publication Certificate

- High visibility of your Published work

Website: www.actascientific.com/

Submit Article: www.actascientific.com/submission.php

Email us: editor@actascientific.com

Contact us: +919182824667 